\section{Acute Onset of Polyarthralgia and High Anti-Cyclic Citrullinated Peptide Antibodies in a Case of Idiopathic Granulomatous Hypophysitis}

\section{To the Editor:}

Idiopathic granulomatous hypophysitis (IGH) is a very rare autoimmune disease of the pituitary gland that leads to a spectrum of pituitary hormone deficiencies of varying severity. We describe an unusual case of a 45-yearold man presenting with acute onset of peripheral arthralgia and diffuse myofascial pain with high anti-cyclic citrullinated peptide (CCP) antibodies and negative laboratory values for antinuclear antibodies (ANA), rheumatoid factor (RF), and antineutrophil cytoplasmic antibodies (ANCA), followed by panhypopituitarism caused by IGH. The anti-CCP antibodies, measured by a third-generation anti-CCP antibodies assay (INOVA), were highly elevated (411 units $/ \mathrm{ml},<20$ negative).

Anti-CCP positivity and its diagnostic value is best known in patients with rheumatoid arthritis (RA). Anti-CCP antibodies have a positive predictive value of $87.9 \%$ for RA. The sensitivity of anti-CCP antibodies for the diagnosis of RA is $77 \%$ and the specificity for RA is $86.1 \%{ }^{1}$. A relatively high frequency of anti-CCP antibodies has also been reported in patients with non-RA connective tissue disorders such as systemic lupus erythematosus (SLE; 15\%), Sjögren's syndrome (SS; 14\%), polymyositis/dermatomyositis (23\%), and scleroderma (16\%). The median level of anti-CCP antibodies, however, was lower in these non-RA patients (7-35 units per ml) compared to patients with RA (100 units per $\mathrm{ml}$ or more $)^{2}$.

The acute onset of polyarthralgia and elevated anti-CCP antibodies will be discussed in relation to the case. In our patient the diffuse myofascial pain and arthralgia may, in part, be associated with hypothyroidism. Our review of the literature has not yielded a similar clinical presentation of IGH. The defining pathological feature and treatment of IGH are reviewed.

A 45-year-old man was admitted to hospital for evaluation of diffuse myofascial pain and peripheral arthralgia. The diffuse myofascial pain and peripheral arthralgia started overnight 4 weeks prior to admission, increased during physical exercise, and resulted in decreased muscular strength and inability to work. He denied any symptoms of morning stiffness or of a previous infection, fever, or any skin lesions. However, mild anorexia with substantial weight loss of $7 \mathrm{~kg}$ over 4 weeks was reported. Clinical examination showed a patient in good general condition but with painful metacarpophalangeal joints, metatarsophalangeal joints, and wrists on both sides. Subsequently, both ankle joints became swollen. Laboratory investigation showed slightly elevated monocytes (11.7\%) and highly elevated anti-CCP antibodies (411 units). ANA, RF, and ANCA were negative. Liver and kidney function, C-reactive protein, and erythrocyte sedimentation rate were all within normal range. Plain radiography of both hands, shoulders, and the spine showed neither erosions nor degenerative changes or calcifications.

Table 1. Endocrine evaluation.

\begin{tabular}{lccc}
\hline & Initial evaluation & $\begin{array}{c}\text { Second evaluation } \\
\text { 3 wks later }\end{array}$ & Normal range \\
& $<0.03$ & 0.01 & $0.35-4.5 \mathrm{mU} / \mathrm{ml}$ \\
TSH & 11.0 & 7.7 & $9.5-25 \mathrm{pmol} / 1$ \\
FT4 & 8.1 & & $2.9-6.6 \mathrm{pmol} / 1$ \\
FT3 & $<20$ & & $<35 \mathrm{IU} / \mathrm{ml}$ \\
TPO & $<10$ & 32 & $<10 \mathrm{IU} / \mathrm{ml}$ \\
TSI & 1.0 & $2.2-15 \mathrm{umol} / 1$ \\
Morning Cortisol & 0.1 & $1.1-8.8 \mathrm{U} / 1$ \\
DHEA-S & 1.3 & $1.4-13.6 \mathrm{U} / 1$ \\
LH & $<0.3$ & $10-30 \mathrm{nmol} / 1$ \\
FSH & 144 & $101-267 \mathrm{ng} / \mathrm{ml}$ \\
Total Testosterone & 19.5 & $2.6-18.1 \mu \mathrm{g} / 1$ \\
IGF-1 & &
\end{tabular}

Initial thyroid evaluation (Table 1) showed very low thyroid-stimulating hormone $(\mathrm{TSH} ;<0.03 \mathrm{mU} / \mathrm{l})$ and slightly elevated fT3 $(8.1 \mathrm{pmol} / \mathrm{l})$ together with fT4 in the low normal range (11.0 pmol/l). TSH receptor and thyroid peroxidase (TPO) antibodies were negative. He was evaluated with a thyroid ultrasound and scintigraphy within a week after the initial thyroid evaluation. The ultrasound was normal. Scintigraphy showed a tracer (99m-Tc-pertechnetate) uptake in the lower normal range (0.6\%). Based on these findings a thyrotoxic phase of an antibody-negative thyroiditis seemed unlikely but could not be excluded, and it may have contributed to the weight loss. Later in the course of the disease, however, he had clear evidence of secondary hypothyroidism (Table 1).

In the course of the evaluation he complained of persistent muscle and articular pain, pronounced fatigue, and decreasing body weight. He also reported polyuria and polydipsia. In summary, the laboratory values (Table 1) showed panhypopituitarism. The diagnosis of diabetes insipidus was based on clinical criteria. Visual field and acuity were normal. Magnetic resonance images revealed an intrasellar mass measuring $1.5 \times 1.5 \times 1.5$ $\mathrm{cm}$ with a thickened infundibular stalk, without compression of the optic chiasm. The normally high signal intensity of the posterior pituitary on the T1-weighted images was absent (Figure 1). He received substitution with prednisone, levothyroxine, desmopressin, and testosterone undecanoate. Therapy with prednisone was started at $40 \mathrm{mg}$ daily, reduced to $20 \mathrm{mg}$ daily after 4 weeks, and further stepwise reduced to $7.5 \mathrm{mg}$ daily.

Due to rapidly progressive panhypopituitarism, exploration of the intrasellar mass was undertaken transphenoidally. There were no surgical complications. Histopathologically the diagnosis of granulomatous hypophysitis with abundant epithelioid, noncaseating granulomas and multinuclear giant cells of Langhans type was made (Figure 2). The anterior lobe parenchyma was almost entirely destroyed. The extensive search for an associated systemic granulomatous disease such as tuberculosis, syphilis, sarcoidosis, histiocytosis X and Morbus Crohn was negative. The diagnosis of IGH was therefore made. After a followup of 8 months the patient still needs hormonal substitution, but the presenting symptoms of diffuse myofascial pain and peripheral arthralgia have disappeared.

He first presented with acute onset of polyarthralgia associated with prominent myalgia, fatigue, and weight loss followed by arthrosynovitis. Peripheral arthralgia with an increased anti-CCP antibody level is very suggestive for RA, since anti-CCP antibodies can be an early finding in RA and can even antedate the onset of disease ${ }^{3}$. Positive anti-CCP antibody level may also be detected in non-RA connective tissue disorders such as SLE, SS, polymyositis/dermatomyositis, and scleroderma ${ }^{2}$ and indicate an inflammation-associated phenomenon seen in an abnormal immune response ${ }^{4}$. A common pathological background between RA and IGH has not been described to date. An association with autoimmune diseases including RA is established for patients with autoimmune lymphocytic hypophysitis ${ }^{5}$. Since our patient rapidly developed progressive panhypopituitarism, acute glucocorticoid insufficiency could have provoked an unknown immunologically mediated condition ${ }^{6}$. In our patient diffuse myofascial pain and arthralgia may, in part, be associated with hypothyroidism? ${ }^{7}$.

IGH is a very rare autoimmune disorder of the pituitary gland with varying severity and spectrum of pituitary hormone deficiencies. The typical clinical picture of IGH comprises symptoms of pituitary mass lesion, most frequently headache and visual impairment ${ }^{8}$. The defining pathological feature is the formation of noncaseating granulomas, consisting of epithelioid granulocytes and multinucleated giant cells. T cell infiltrates also occur. The immune infiltrate comprises activated folliculo-stellate cells (FSC) of "true dendritic" type. The FSC are considered antigen-presenting cells, capable of processing and displaying antigens on MHC class II molecules, and initiate primary T lymphocyte responses ${ }^{9}$. The mechanism proposed in RA is very similar as the inflammatory process is understood as $\mathrm{T}$ cell-mediated as well. The number of $\mathrm{T}$ cells correlates negatively with the degree of fibrosis in IGH. An unknown autoantigen from pituitary cells is implicated in the pathogenesis of hypophysitis ${ }^{10}$. Current treatment of IGH is symptomatic and supportive. Mass reduction can be 


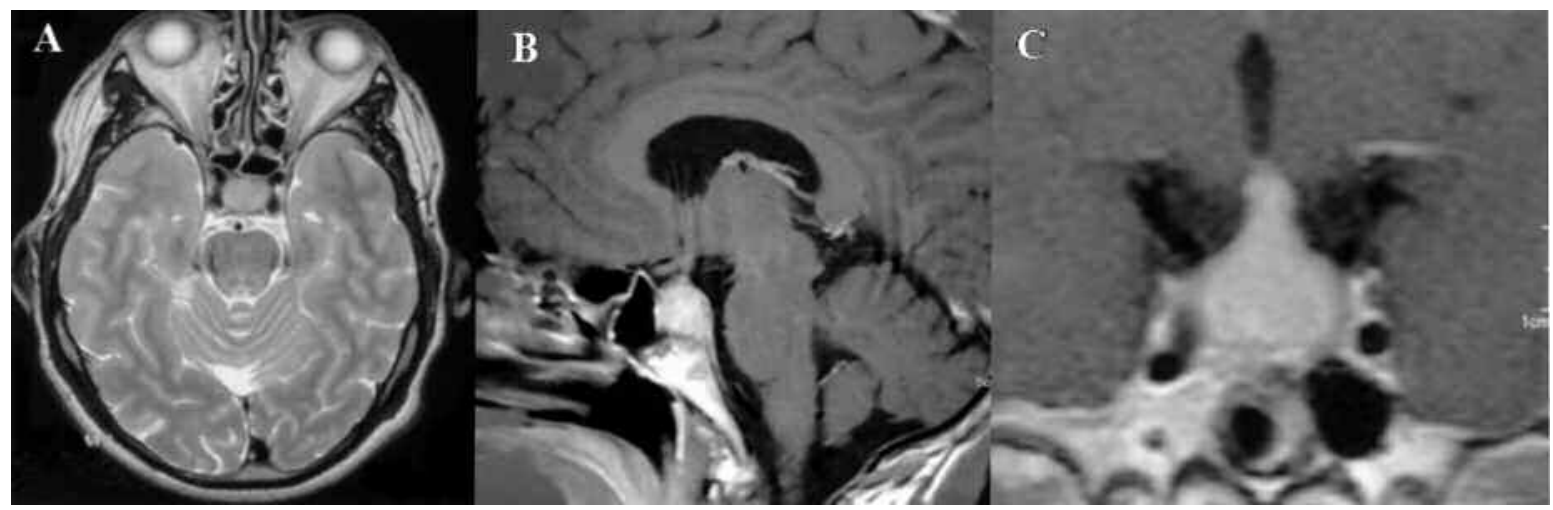

Figure 1. A. T2-weighted axial MRI shows an enlarged pituitary gland with absence of hyperintense signal of the posterior pituitary. B. After administration of gadolinium the T1-weighted sagittal image shows a homogenous enhancement of the enlarged pituitary gland. C. A prominent and thickened infundibular stalk with an enlarged pituitary gland is shown in the T1-weighted coronal image without compression of the optic chiasm.

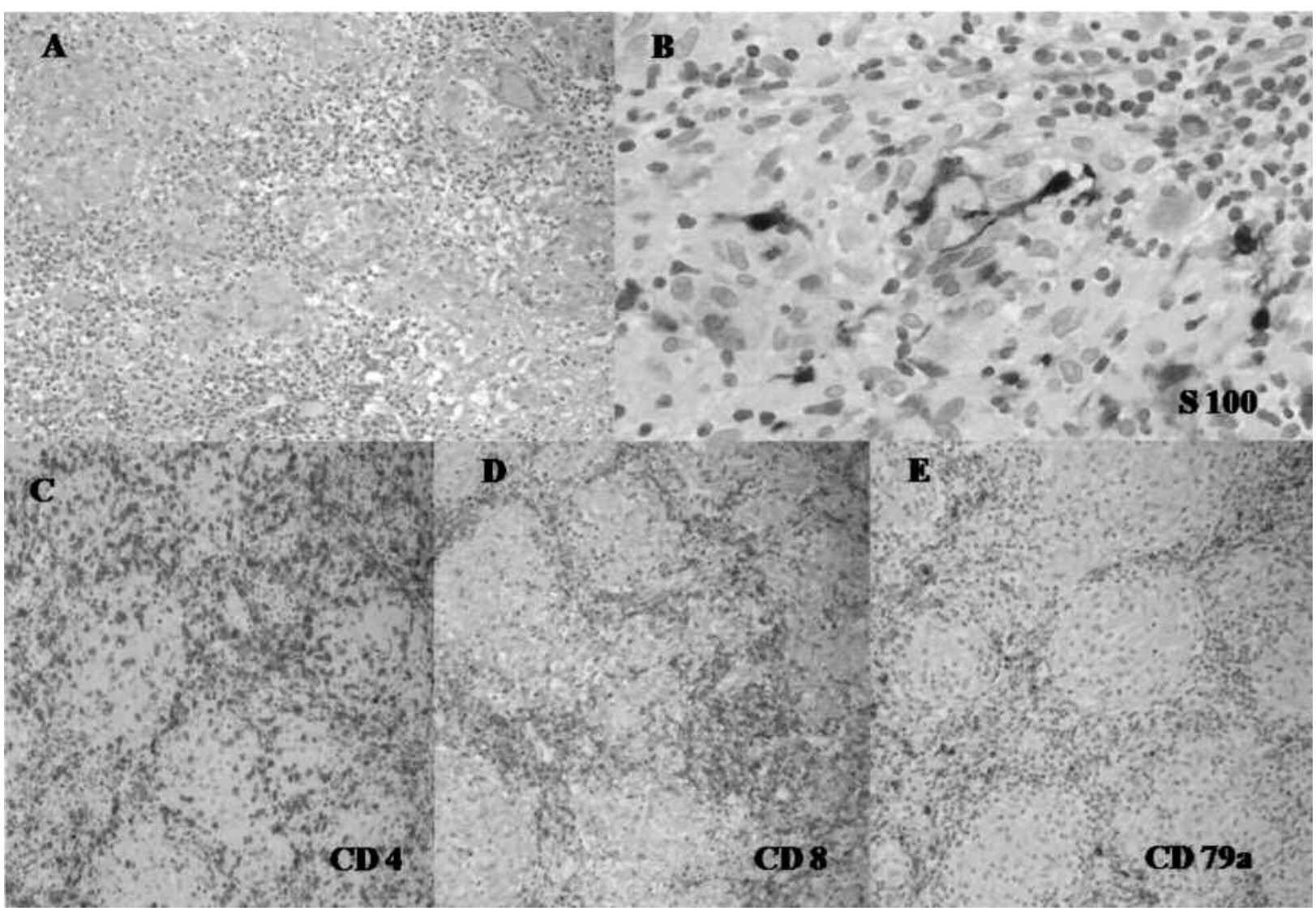

Figure 2. Histology of IGH. A. Overview to show near-complete replacement of pituitary parenchyma by a profusion of noncaseating granulomas, some of which tend to coalesce. B. An otherwise scarcely distinguishable participant of granulomas, folliculo-stellate cells display an eye-catching set of dendritic processes on immunostaining for S100 protein. C and D. Between individual granulomas, the native architecture of the anterior pituitary is being obscured by a dense infiltrate in which T lymphocytes prevail. E. Less than $20 \%$ of lymphocytes were of B cell lineage.

achieved by pituitary surgery, radiotherapy, or lympholytic drugs (glucocorticoids, azathioprine, or methotrexate). Glucocorticoids can be effective both as antiinflammatory agents and as replacement of defective adrenal function ${ }^{8}$. Analogous to the immunomodulation of T cell-mediated inflammatory diseases such as RA, cytokine-blocking therapies or even more adequate $\mathrm{T}$ cell inhibition, interfering with the CD80/CD28 pathway, would be of therapeutic interest ${ }^{11}$.
MURIEL BABEY, MD, Research Fellow, Division of Endocrinology, Diabetes and Clinical Nutrition and Department of Neurosurgery, Inselspital; DANIEL AEBERLI, MD, Senior Rheumatologist, Division of Rheumatology and Clinical Immunology, Inselspital; ISTVAN VAJTAI, MD, Senior Pathologist, Institute of Pathology; RAHEL SAHLI, MD, Senior Endocrinologist, Division of Endocrinology, Diabetes and Clinical Nutrition, Inselspital, University of Bern, Bern, Switzerland. Address 
reprint requests to Dr. D. Aeberli, Division of Rheumatology and Clinical Immunology, Inselspital, 3010 Bern, Switzerland.

E-mail: daniel.aeberli@insel.ch

\section{ACKNOWLEDGMENT}

We thank Prof. R.W. Seiler, Chairman of Neurosurgery, University of Bern, Inselspital; P.D.E. Christ, Senior Endocrinologist, Division of Endocrinology and Diabetes, University of Bern, Inselspital; and Dr. B. Müller, Endocrinologist in Private Practice, Bern, Switzerland for their contribution to the case report.

\section{REFERENCES}

1. Kitahara K, Tagaki K, Kusonoki Y, et al. Clinical value of second- and third-generation assays of anti-cyclic citrullinated peptide antibodies in rheumatoid arthritis. Ann Rheum Dis 2008;67:1059-60.

2. Matsui T, Shimada K, Ozawa N, et al. Diagnostic utility of anti-cyclic citrullinated peptide antibodies for very early rheumatoid arthritis. J Rheumatol 2006;33:2390-7.

3. Rantapaa-Dahlqvist S, de Jong BA, Berglin E, et al. Antibodies against cyclic citrullinated peptide and IgA rheumatoid factor predict the development of rheumatoid arthritis. Arthritis Rheum 2003;48:2741-9.

4. Vossenaar ER, Smeets TJ, Kraan MC, Raats JM, van Venrooij WJ, Tak PP. The presence of citrullinated proteins is not specific for rheumatoid synovial tissue. Arthritis Rheum 2004;50:3485-94.
5. Thodou E, Asa SL, Kontogeorgos G, Kovacs K, Horvath E, Ezzat S. Clinical case seminar: lymphocytic hypophysitis: clinicopathological findings. J Clin Endocrinol Metab 1995;80:2302-11.

6. Sahli R, Diem P, Christ ER. Endogenous hypercortisolism and immunologically-mediated disease: three cases. Dtsch Med Wochenschr 2005;130:2316-8.

7. Georg G. Hypothyroidism presenting as puzzling myalgias and cramps in 3 patients. J Clin Rheumatol 2007;13:273-5.

8. Caturegli P, Newschaffer C, Olivi A, Pomper MG, Burger PC, Rose NR. Autoimmune hypophysitis. Endocr Rev 2005;26:599-614.

9. Vajtai I, Kappeler A, Sahli R. Folliculo-stellate cells of "true dendritic" type are involved in the inflammatory microenvironment of tumor immunosurveillance of pituitary adenomas. Diagn Pathol 2007;2:20.

10. Caturegli P. Autoimmune hypophysitis: an underestimated disease in search of its autoantigen(s). J Clin Endocrinol Metab 2007;92:2038-40.

11. Kremer JM, Dougados M, Emery P, et al. Treatment of rheumatoid arthritis with the selective costimulation modulator abatacept: twelve-month results of a phase iib, double-blind, randomized, placebo-controlled trial. Arthritis Rheum 2005;52:2263-71.

J Rheumatol 2009;36:1; doi:10.3899/jrheum.080408 